\title{
Effectiveness of an exercise program on postural control in frail older adults
}

\author{
This article was published in the following Dove Press journal: \\ Clinical Interventions in Aging \\ 17 December 2012 \\ Number of times this article has been viewed
}

\author{
Fábio Marcon Alfieri ${ }^{1,2}$ \\ Marcelo Riberto 3 \\ Àngels Abril-Carreres ${ }^{4}$ \\ Maria Boldó-Alcaine ${ }^{4}$ \\ Elisabet Rusca-Castellet ${ }^{4}$ \\ Roser Garreta-Figuera ${ }^{4}$ \\ Linamara Rizzo Battistella ${ }^{5}$ \\ 'São Paulo Adventist University \\ Center, São Paulo, Brazil; ${ }^{2}$ Institute \\ of Physical and Rehabilitation \\ Medicine Hospital of Clinics, \\ University of São Paulo, Brazil; \\ ${ }^{3}$ School of Medicine in Ribeirão \\ Preto, University of São Paulo, Brazil; \\ ${ }^{4}$ University Hospital Mútua Terrassa \\ Department of Rehabilitation, \\ University of Barcelona, Barcelona, \\ Spain; ${ }^{5}$ School of Medicine, Institute of \\ Physical Medicine and Rehabilitation, \\ Clinics Hospital of University of São \\ Paulo, São Paulo, Brazil
}

Background: Exercise programs have proved to be helpful for frail older adults. This study aimed to investigate the effects of an exercise program with a focus on postural control exercises in frail older adults.

Method: Twenty-six older adults (76.7 \pm 4.9 years) deemed clinically stable, chosen from the Falls Unit, University Hospital Mútua Terrassa, Barcelona, Spain, participated in this singlegroup study. Volunteers' postural control was evaluated using the Timed Up and Go test (TUG) and the Guralnik test battery, and their static and dynamic posturography were evaluated using the Synapsys Posturography System ${ }^{\circledR}$. These evaluations were performed before and after the intervention program, which included an educational session and two weekly 1-hour sessions over an 8-week period of stretching exercises, proprioception, balance, and motor coordination. Data were analyzed using the Student's $t$-test or the Wilcoxon test, with a significance level of 5\%.

Results: The TUG and Guralnik tests did not show significant differences. Concerning static posturography, there was improvement in the base of support $(P=0.006)$, anteroposterior displacement with eyes open $(P=0.02)$ and closed $(P=0.03)$, and the total amplitude of the center of pressure with eyes closed $(P=0.02)$. Regarding dynamic posturography, a decrease of the oscillation speed in the anteroposterior direction $(P=0.01)$ was observed in individuals with their eyes open.

Conclusion: The program used in this study was safe and was able to promote some improvement in postural control, especially in the anteroposterior direction and in the base of support. However, it is noteworthy that further improvements could be obtained from a program of longer duration and greater frequency.

Keywords: balance, aging, intervention, falls

\section{Introduction}

The aging process occurs around the world and is accompanied by changes in neuromuscular, somatosensory, vestibular, and visual systems associated with sedentary lifestyles or diseases, and results in decreased postural control and falls. ${ }^{1,2}$ Some $30 \%$ of the elderly fall about once a year, and in frail individuals, this number is greater, as pointed out in a study that found $80 \%$ of seniors who attended rehabilitation services had fallen in the last year. ${ }^{3-5}$

In turn, falls increase the number of injuries and deaths, making this a public health problem in the population. Falls resulting in injuries such as fractures, psychological disorders, and increased use of health services (the leading cause of emergencydepartment visits), generate costs for both the individual and for health services, and can result in not intentional death for older adults. ${ }^{5,6}$
Correspondence: Fábio Marcon Alfieri Paulo, Estrada de Itapecerica 5859, São Paulo - SP, Brasil, 05828-00 I

Tel +55 II 2 I 286000

Fax +55 II 21286465

Email fabio.alfieri@unasp.edu.br 
Interventions that are effective for postural control in elderly people are needed to improve performance in daily living activities and to prevent further falls. Regular performance of exercises that improve postural control and reduce the risk of falls is the most effective way to prevent them. ${ }^{7,8}$ A variety of exercises involving gait, balance, coordination, functional tasks, strength training, stretching, 3D exercises (including tai chi, qi gong, dance, and yoga), and multisensory exercises, can enhance muscle strength, balance, and mobility in the elderly, reducing the risk of falls..$^{9,10}$ However, a large portion of these studies is performed in elderly individuals considered healthy and without risk of falls: it is desirable for further research to obtain new insights into the mechanisms related to different types of exercise and their impact on stability in individuals with a risk of falls. ${ }^{11}$

It is believed that balance improvement may be related to fall reduction, and we hypothesized that multifactorial interventions can be promising and effective in this matter; thus, the aim of this study was to investigate the effects of an exercise program that focused on postural control exercises in frail older adults.

\section{Methods}

This single-group study was approved by the Ethics Committee of the University Hospital Mútua Terrassa, Barcelona, Spain, and all participants signed an informed consent form before being accepted into the study. Persons of both sexes, aged 60 years and over, who were being treated in the Falls Unit, University Hospital Mútua Terrassa, Barcelona, Spain, were invited to participate. These were the older adults living in the community; they were referred to the unit by a physician or other professional who had recognized that these individuals were likely to fall. This likelihood was assessed due to clinical characteristics and the presence of diseases that could cause falls, which can be defined as events in which an individual inadvertently comes to rest at a lowerthan-usual level. ${ }^{12}$

In the Falls Unit, a geriatrician, physiatrist, physical therapist, and nurse work in a multidisciplinary team and perform general evaluations of patients. In order to be accepted into this unit, the patient must have a history of falls within the last year or must be at risk of falling. To assess the risk of falls as well as the overall health status of the volunteer, the unit conducts a complete physical examination that emphasizes cardiovascular, neurological, and locomotor disorders to establish the risk of falling. ${ }^{13}$ If clinical stability is noticed (stable hemodynamic conditions such as controlled blood pressure), the patient is referred to the intervention group to begin the exercise program. No individuals participated in this study who had cognitive deficits (assessed during the medical visit to verify orientation and ability to understand simple commands) or diseases that were not under control and that impeded the performance of exercises. To assess the participants' levels of physical activity, a short form of the International Physical Activity Questionnaire (IPAQ) ${ }^{14}$ was applied. Balance ability was also measured using the Tinetti scale. ${ }^{15}$ Table 1 shows the characteristics of the volunteers in relation to gender, average age, and level of physical activity distribution, as well as diseases and clinical conditions that were present in more than three cases among the study volunteers. Problems such as cataracts, glaucoma, cognitive impairment, venous insufficiency, fibromyalgia, stable cardiovascular disease, diabetes, and mild subcortical brain atrophy were also found, but were seen in fewer than three cases.

In order to verify the changes in postural control after the exercise program, the volunteers were subjected to the following assessments:

- The timed "Up and Go" (TUG) test required the subject to stand up, walk 3 meters (10 feet), turn, walk back, and sit down. The time taken to complete the test is strongly correlated to level of functional mobility. ${ }^{16}$

- The Guralnik test battery ${ }^{17}$ consisted of three items: static balance, ability to rise from a chair, and walking speed. Each item is scored on a scale of 0 to 4 . Static balance

Table I General characteristics of group

\begin{tabular}{ll}
\hline & $\begin{array}{l}\text { Group } \\
\text { Number/\% }\end{array}$ \\
\hline $\mathrm{N}$ & 26 \\
$\mathrm{~F} / \mathrm{M}$ & $25 / \mathrm{I}$ \\
$\mathrm{Age}($ years $)$ & $76.7 \pm 4.9$ \\
$\mathrm{BMI}\left(\mathrm{Kg} / \mathrm{cm}^{2}\right)$ & $29.5 \pm 2.8$ \\
Level of physical activity & \\
Low & $11 / 42.3 \%$ \\
Moderate & $11 / 2.3 \%$ \\
High & $4 / 15.3 \%$ \\
Diseases/clinical conditions & \\
Instability & $14 / 53.8 \%$ \\
Urinary incontinence & $13 / 50 \%$ \\
Sensory deficit & $14 / 53.8 \%$ \\
Polypharmacy & $14 / 53.8 \%$ \\
Depression & $11 / 42.3 \%$ \\
Fear of falling & $10 / 38.4 \%$ \\
Hypertension & $13 / 50 \%$ \\
Arthropathy & $9 / 34.6 \%$ \\
Osteoporosis & $11 / 42.3 \%$ \\
Falls within the last year & $24 / 92.3 \%$ \\
Fractures related to falls & $7 / 26.9 \%$ \\
\hline Abbrevations: BMl, & \\
\hline
\end{tabular}

Abbreviations: BMI, body mass index; $F$, female; $M$, male; $N$, number of subjects. 
is evaluated using three different, progressively more difficult stances, starting with the side-by-side stance, moving to the semi-tandem stance, and ending with the tandem stance. To test the ability to rise from a chair, participants are asked to sit with their arms folded across their chests in a straight-backed chair placed with its back against a wall, and then to stand up from the chair one time. If they are successful in performing this task, they are asked to stand up and sit down as quickly as possible five times in a row. Timing starts at the instructor's signal and stops at the fifth stand. For the walking speed test, participants are instructed to walk a distance of 8 feet (2.5 meters) at their normal pace using any walking aid(s) that they typically require.

- Balance evaluation used posturography with the static and dynamic system Synapsys Posturography System ${ }^{\circledR}$ (SPS $^{\circledR}$, SYNAPSIS, Marseille, France). In order to evaluate balance, the individual stood on the platform - fixed or unstable - with his/her feet aligned to previously determined markings, corresponding to foot size. Different evaluations were performed barefoot and in a standing position: 60 seconds for the evaluations with eyes open and 20 seconds for those with eyes closed. The following parameters were studied: base of support with eyes open $\left(\mathrm{mm}^{2}\right)$, which is equivalent to the stability limit; the motion parameters of center of gravity in the $x$-axis (mediolateral) and y-axis (anteroposterior) (mm); a statokinesigram (SKG), which is a graph of successive positions of center of pressure recorded by the platform; and a longitudinal SKG (LSKG), for the longitudinal displacement of the center of pressure during the tests. In dynamic tests, the oscillation speed of the platform $(\%)$ and the maximum inclination of the platform $\left(^{\circ}\right)$ were evaluated.

The goal during the reviews of posturography is to remain as stable (still) as possible. Clinical evaluations (TUG and Guralnik) were made on one day, and on another day, the posturography assessments were made. Initial assessments were made in the week prior to the start of the program and the final assessments in the week following the end of the program. The exercise program was conducted in classes.

These assessments were performed before and after an intervention program consisting of an educational session, in which the participants were taught how to prevent falls.

In this session, all volunteers watched an educational video explaining how the elderly should proceed to carry out day-to-day activities, for example, how to get in and get out of a shower box, how to get up and sit down in a bed, how to distribute one's weight when carrying heavy objects, and the importance of wearing appropriate shoes (with nonslip soles).

After this session, the exercise program began. The program consisted of two weekly 1-hour sessions over an 8 -week period. Bats and balls were used for the execution of the exercises.

The exercise program began with warm-up exercises ( 5 minutes). For this, the volunteers performed exercises walking sideways and walking forward and backward, in association with musical stimuli. After that, they performed stretching exercises (20 minutes) for the hip, knee, ankle, and trunk muscles. Next, for 25 minutes, there were exercises for motor coordination and balance using balls and bats in movements associated with recreational activities: throwing balls at each other and hitting balls with a bat in one's hands. Some exercises were also done with both eyes closed, for example, keeping one foot in front of the other. This was followed by a slowdown and relaxation period of 5 minutes, during which they performed breathing exercises associated with the upper limbs. The progression of the exercises was tailored to each volunteer, according to how easily each exercise could be performed, for example, by increasing the time a volunteer spent with his or her eyes closed while positioned with one foot in front of the other.

Data analysis was performed using GraphPad In Stat Software Inc (San Diego, CA, USA). Results were stated as mean and standard deviation. To compare the data, before and after the program, the paired $t$-test and Wilcoxon test were used, according to the data characteristics. The significance level was set at $5 \%$.

\section{Results}

Fifty four people being treated in the Falls Unit were approached, 28 of whom were not included in this study, since they did not meet our inclusion criteria. Of the 26 participants who started the exercise program, three were excluded: one for missing the last evaluation, one due to knee pain (pain that was not related to the exercise program), and one who was not willing to perform the exercises. Comparison of pre- and postintervention considered only the values of the 23 individuals who started and finished the intervention.

No statistically significant improvements in the outcomes of the TUG or Guralnik test battery were observed. Table 2 shows the results of the clinical trial evaluations regarding balance. The time of the TUG test decreased 1.57 seconds; the Guralnik test battery showed a small increase of 0.57 points, with no significant improvement. 
Table 2 Results of clinical evaluations on postural control before and after intervention program (mean and standard deviation)

\begin{tabular}{lrrl}
\hline & Before & After & $P$-value \\
\hline TUG (s) & $17.92 \pm 9.42$ & $16.35 \pm 7.55$ & $0.19^{*}$ \\
Guralnik & $6.76 \pm 2.10$ & $7.22 \pm 2.34$ & $0.21^{*}$ \\
\hline
\end{tabular}

Note: *Paired t-test.

Abbreviations: TUG, timed up and go test; s, seconds; Guralnik, Guralnik test battery.

When analyzing the static posturography data, an improvement was noticed in the base of support and anteroposterior displacement (y-axis) following the intervention. There was also improvement in the SKG graph of successive positions of the center of pressure recorded by the platform while the participant performed the exercises with eyes closed, as seen in Table 3.

Concerning dynamic posturography, a significant decrease in the oscillation rate of the platform in the anteroposterior direction was seen when subjects had their eyes open, as shown in Table 4.

\section{Discussion}

This study aimed to investigate the effects of an exercise program with a focus on postural control exercises in frail older adults. Using the data collected from the clinical trial evaluations (Guralnik test battery and TUG test), it was not possible to confirm improvement in the volunteers' postural control. When the older adults were assessed using direct parameters such as the balance platform (posturography), the stability limit observed during the static evaluation, as well as the decrease in displacement of the center of pressure in the anteroposterior direction, showed significant differences after the intervention program. Concerning dynamic equilibrium,

Table 3 Characteristics related to static and dynamic posturography (mean and standard deviation)

\begin{tabular}{lccl}
\hline & Before & After & P-value \\
\hline Base sust EO $\left(\mathrm{mm}^{2}\right)$ & $9115.36 \pm 4143$ & $\mathrm{II} 5 \mathrm{II} .8 \mathrm{I} \pm 5849.5$ & $0.006^{*}$ \\
Mean x-axis EO $(\mathrm{mm})$ & $2.60 \pm 6.72$ & $4.55 \pm 7.46$ & $0.33^{*}$ \\
Mean y-axis EO $(\mathrm{mm})$ & $-35.12 \pm 15.12$ & $-30.08 \pm 12.45$ & $0.02^{*}$ \\
SKG (super) EO $(\mathrm{mm})$ & $384.72 \pm 253.04$ & $368.09 \pm 197.07$ & $0.78^{*}$ \\
Long SKG EO $(\mathrm{mm})$ & $453.29 \pm 152.38$ & $524.84 \pm 217.80$ & $0.06 *$ \\
Mean x-axis EC $(\mathrm{mm})$ & $2.99 \pm 6.46$ & $5.42 \pm 7.39$ & $0.1 I^{*}$ \\
Mean y-axis EC $(\mathrm{mm})$ & $-32.11 \pm 14.64$ & $-28.03 \pm 10.48$ & $0.03^{*}$ \\
SKG (super) EC $(\mathrm{mm})$ & $742.27 \pm 572.84$ & $520.31 \pm 351.79$ & $0.02^{*}$ \\
Long SKG EC $(\mathrm{mm})$ & $828.90 \pm 437.86$ & $801.75 \pm 410.11$ & $0.62^{*}$ \\
\hline
\end{tabular}

Note: *Paired $t$-test.

Abbreviations: EO, eyes open; EC, eyes closed; mean x-axis, mediolateral movement; mean y-axis, anteroposterior movement; Sust, sustention; SKG, statokinesigram (graph of successive positions of center of pressure); long, LSKG-longitudinal displacement of center of pressure.
Table 4 Characteristics related to dynamic posturography (mean and standard deviation)

\begin{tabular}{llll}
\hline & Before & After & P-value \\
\hline VplatAPEO $(\% / s)$ & $2.5 \pm 0.7$ & $2.1 \pm 0.6$ & $0.0 I^{*}$ \\
VplatAPEC $(\% / s)$ & $4.6 \pm 1.1$ & $4.8 \pm 1.5$ & $0.37^{*}$ \\
VplatLMEO $(\% / s)$ & $2.4 \pm 0.7$ & $2.3 \pm 1.0$ & $0.75^{*}$ \\
VplatLMEC $(\% / s)$ & $3.7 \pm 0.8$ & $3.8 \pm 1.1$ & $0.52^{*}$ \\
IncIMeanPlatAPEO $\left({ }^{\circ}\right)$ & $1.4 \pm 0.8$ & $1.2 \pm 0.8$ & $0.60^{*}$ \\
IncIMeanPlatAPEC $\left({ }^{\circ}\right)$ & $2.9 \pm 1.0$ & $3.4 \pm 2.9$ & $0.53^{* *}$ \\
IncIMeanPlatLMEO $\left({ }^{\circ}\right)$ & $1.6 \pm 0.8$ & $1.4 \pm 0.8$ & $0.38^{*}$ \\
IncIMeanPlatLMEC $\left({ }^{\circ}\right)$ & $2.7 \pm 0.9$ & $2.3 \pm 0.7$ & $0.07^{*}$ \\
\hline
\end{tabular}

Notes: *Paired $t$-test; **Wilcoxon, $\%$ s -degree for seconds, ${ }^{\circ}$-degree.

Abbreviations: EO, eyes open; EC, eyes closed; V, speed; incl, inclination; LM, mediolateral mean; AP, anteroposterior mean; $\mathrm{V}$, velocity; plat, platform.

decreased speed was observed when subjects were on the platform in the anteroposterior direction with eyes open.

In a previous study of a population similar in age to the individuals in this study, the TUG test was performed in about 9.2 seconds. ${ }^{18}$ The volunteers in this study took 8.7 seconds longer (ie, 17.92 seconds) before intervention. Even after the intervention program, the time taken to perform the test (16.35 seconds) still represented a high risk for falls. ${ }^{19}$

Unexpectedly, the TUG test performance time did not decrease significantly after the intervention, showing that perhaps the time of intervention, the type of stimulus, or even the characteristics of the sample (which had many associated diseases), may have interfered with the results regarding functional mobility. In just ten sessions, Cardoso and Alfieri, ${ }^{20}$ and subsequently Alfieri et $\mathrm{al}^{21}$ in 24 sessions, were able to confirm improvement in functional mobility and postural control using general exercises that emphasized proprioceptive stimulus (by using healthy elderly individuals, however). Although programs that consisted of an 8-week exercise program for frail older adults have achieved improvements in the balance of their volunteers, ${ }^{11}$ the results of this study indicate that short programs for frail elderly individuals can promote improvements in relation to postural control, when evaluated with direct measures such as posturography.

The lack of improvement in the Guralnik test battery results may be correlated to the lack of improvement in the TUG test, since part of this test battery assesses lower-limb muscle strength and gait speed, which are items included in the TUG test.

In this study, an assessment of the base of support, which analyzes the stability limits of the volunteers, showed a significant increase. This improvement, obtained from the static posturography evaluation, which measures displacement and body oscillations in relation to vertical position, ${ }^{13}$ 
is important, since the type of stability contributes directly to the independence of the elderly person. Displacement and body oscillations occur during the daily tasks performed by the elderly, such as using public transportation and moving to reach an object, among others. ${ }^{22}$

Another positive factor observed after the exercise program was the improvement of displacement in the anteroposterior direction with eyes open or closed. This finding is important because the elderly are likely to have improved plantar flexor and dorsiflexor muscle action, which are part of the ankle's strategy for maintaining postural control..$^{23-25}$ This strategy is the first action the ankle takes in cases of anterolateral balance disorder in the upright position. ${ }^{26,27}$

Interestingly, an improvement regarding the reduction of oscillation of the center of pressure was noticed when the volunteers were evaluated with their eyes closed, contradicting the fact that in situations where the eyes are closed, the results are usually worse than when the eyes are open. ${ }^{28,29}$ It is believed that this type of improvement is important in the life of older adults, because activities such as getting out of bed at night may become less dangerous (since postural control has improved), even without aid from this part of the sensory system.

Regarding the evaluation of dynamic balance, a significant decreased oscillation rate of the platform in the anteroposterior direction with eyes open was seen, indicating that the stimuli generated by the exercise program resulted in improved balance in a dynamic situation, because the greater pressure center oscillation implies a lower balance. ${ }^{26}$ However, this was the only improvement in dynamic balance found in this study.

Concerning the execution of intervention programs for older adults with altered mobility and balance, reviews show that the inclusion of two or more types of exercise, such as strength, balance, flexibility, or resistance, can reduce fall rates. ${ }^{9,30,31}$ Thus, the exercise program used in this study, which included flexibility, balance, and motor coordination, was in accordance with standard recommendations; however, research studies that focused on strengthening and balance training showed that these helped prevent falls in older adults. ${ }^{32,33}$ Thus, the lack of this specific muscle-strengthening component in the present study may have contributed to the results being less satisfactory. This is probably because people over 70 years old who do engage in balance and resistance training are much more likely to be healthy and functionally capable than those who do not. ${ }^{33}$ Improvements in postural control from programs that seek to stimulate balance may be due to increased sensorial stimuli, as well as to better muscular response after performing the exercises. ${ }^{21}$
Therefore, although the program used in this study was safe and showed some improvements in postural control, especially in the anteroposterior direction and base of support, we believe improvements could have been greater in other respects had the postural control exercise program lasted longer, had more frequent sessions, or involved muscle strengthening.

Additional studies with larger sample sizes, or studies using different programs, are recommended to further analyze the results of physical exercise in frail older adults, and to provide more intervention options for improving postural control and preventing falls in this population.

\section{Disclosure}

The authors report no conflicts of interest in this work.

\section{References}

1. Martin JE, Sheaff MT. The pathology of ageing: concepts and mechanisms. J Pathol. 2007;211:111-113.

2. Alfieri FM, Moraes MCL. Envelhecimento e o controle postural. Saúde Coletiva. 2008;4(19):30-33.

3. Tinetti ME, Speechley M, Ginter SF. Risk factors for falls among elderly person living in the community. N Engl J Med. 1988;319:701-707.

4. King MB, Tinetti MG. Falls in community dwelling older persons. JAm Geriatric Soc. 1995;43:1146-1154.

5. Alfieri FM, Soriano CC, Figuera RG, Battistella LR. Aspectos relacionados con caídas y equilibrio de los ancianos residentes en un centro sociosanitario. Rehabilitación (Madr). 2011;45(1):24-28.

6. Shubert TE. Evidence-based exercise prescription for balance and falls prevention: a current review of the literature. Geriatr Phys Ther. 2011;34(3):100-108.

7. Skelton DA. Effects of physical activity on postural stability. Age Ageing. 2001;30(54):33-39.

8. Bassey EJ. Exercise for the elderly: an update. Age Ageing. 2002;31 Suppl 2:S3-S5.

9. Howe TE, Rochester L, Jackson A, Banks PMH, Blair VA. Exercise for improving balance in older people [review]. Cochrane Database Syst Rev. 2011;9(11):CD004963.

10. Alfieri FM, Riberto M, Gatz LS, Ribeiro CPC, Lopes JAF, Battistella LR. Functional mobility and balance in community-dwelling elderly submitted to multisensory versus strength exercises. Clin Interv Aging. 2010;5:181-185.

11. Bulat T, Hart-Hughes S, Ahmed S, et al. Effect of a group-based exercise program on balance in elderly. Clin Interv Aging. 2007;2(4): 655-660.

12. Nnodim JO, Alexander NB. Assessing falls in older adults: a comprehensive fall evaluation to reduce fall risk in older adults. Geriatrics. 2005;60(10):24-28.

13. Lazaro del Nogal M, González-Ramírez A, Palomo-lloro A. Evaluación del riesgo de caídas. Protocolos de valoración clínica. Rev Esp Geriatr Gerontol. 2005;40 Supp1 2:S54-S63.

14. Booth ML. Assessment of physical activity: an international perspective. Res Q Exerc Sport. 2000;71(2):114-120.

15. Tinetti ME. Performance-oriented assessment of mobility problems in elderly patients. J Am Geriatr Soc. 1986;34:119-126.

16. Podsiadlo D, Richardson S. The timed "Up and Go": a test of basic functional mobility for frail elderly persons. J Am Geriatr Soc. 1991;39:142-148.

17. Guralnik JM, Simonsick EM, Ferrucci L, et al. A short physical performance battery assessing lower extremity function: association with self-reported disability and prediction of mortality and nursing home admission. J Gerontol Med Sci. 1994;49:M85-M94. 
18. Bohannon R. Reference values for the Timed Up and Go test: a descriptive meta-analysis. J Geriatr Phys Ther. 2006;29:64-68.

19. Shumway-Cook A, Brauer S, Woollacott M. Predicting the probability for falls in community-dwelling older adults using the timed up and go test. Phys Ther. 2000;80:896-903.

20. Cardoso AS, Alfieri FM. Efectos de un programa de entrenamiento propioceptivo corto en el control postural en personas mayores. Rev Esp Geriatr Gerontol. 2011;46(5):281-285.

21. Alfieri FM, Guirro RRJ, Teodori RM. Postural stability of elderly submitted to multisensorial physical therapy intervention. Electromyogr Clin Neurophysiol. 2010;50(2):113-119.

22. Islam MM, Nasu E, Rogers ME, Koizumi D, Rogers Nl, Takeshima N. Effects of combined sensory and muscular training on balance in Japanese older adults. Prev Med. 2004;39(6):1148-1155.

23. Nagy E, Feher-Kiss A, Márnai B, Domján-Preszner A, Angyan L, Horvath G. Postural control in elderly subjects participating in balance training. Eur J Appl Physiol. 2007;100:97-104.

24. Orr R, Raymond J, Sigh MF. Efficacy of progressive resistance training on balance performance in older adults. Sports Med. 2008;38(4): 317-343.

25. Hue OA, Seynnes O, Ledrole D, Colson SS, Benard PL. Effects of a physical activity program on postural stability in older people. Aging Clin Exp Res. 2004;16(5):1-7.
26. Shumway-Cook A, Woollacott M. Motor Control: Theory and Practical Applications. Baltimore: Williams and Wilkins; 1995.

27. Pinho L, Dias RC, Souza TR, Freire MTF, Tavares CF, Dias JMD. Avaliação isocinética da função muscular do quadril e do tornozelo de idosos que sofreram quedas. Rev Bras Fisioter. 2005;9(1):93-99.

28. Rogers ME, Rogers NL, Takeshima N, Islam MM. Methods to asses and improve the physical parameters associated with fall risk in older adults. Prev Med. 2003;36:255-264.

29. Perrin PP, Gauchard GC, Perrot C, Jeandel C. Effects of physical and sporting activities on balance control in elderly people. $\mathrm{Br} J$ Sports Med. 1999;33(2):121-126.

30. Salzman B. Gait and balance disorders in older adults. Am Fam Physician. 2010;82(1):61-68.

31. Hubbard RE, Fallah N, Searle SD, Mitnitski A, Rockwood K. Impact of exercise in community-dwelling older adults. PLoS ONE. 2009;4(7):e6174.

32. Robertson MC, Devlin N, Scuffham P, Gardner MM, Buchner DM, Campbell AJ. Economic evaluation of a community based exercise programme to prevent falls. J Epidemiol Community Health. 2001;55(8):600-606.

33. Clemson L, Fiatarone Singh MA, Bundy A, et al. Integration of balance and strength training into daily life activity to reduce rate of falls in older people (the LiFE study): randomised parallel trial. BMJ. 2012;345:e4547.
Clinical Interventions in Aging

\section{Publish your work in this journal}

Clinical Interventions in Aging is an international, peer-reviewed journal focusing on evidence-based reports on the value or lack thereof of treatments intended to prevent or delay the onset of maladaptive correlates of aging in human beings. This journal is indexed on PubMed Central, MedLine, the American Chemical Society's 'Chemical Abstracts

\section{Dovepress}

Service' (CAS), Scopus and the Elsevier Bibliographic databases. The manuscript management system is completely online and includes a very quick and fair peer-review system, which is all easy to use. Visit http://www.dovepress.com/testimonials.php to read real quotes from published authors. 